International Journal of Instruction e-ISSN: 1308-1470 • www.e-iji.net

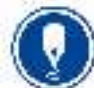

Article submission code: 20200323064423
Received: 23/03/2020

Revision: $21 / 10 / 2020$
April 2021 • Vol.14, No.2

p-ISSN: 1694-609X

pp. 791-810

Accepted: 13/11/2020

OnlineFirst: 26/02/2021

\title{
Flipped Classroom Strategy Based on Critical Thinking Skills: Helping Fresh Female Students Acquiring Derivative Concept
}

\author{
Ali M. Al-Zoubi \\ Dr.. Education College, Yarmouk University, Jordan, ali.m@yu.edu.jo
}

Laiali M. Suleiman

Dr.. Suleiman, Researcher in Teaching Mathematics, Saudi Arabia,

lsolyman@kku.edu.sa

\begin{abstract}
The current study aimed at investigating the impact of Flipped Classroom Strategy by using E-Learning Systems (Blackboard) based on Critical Thinking Skills of the acquisition of fresh female students of the derivative concept of Calculus. To conduct this study, the researchers followed the explanatory sequential mixedmethods by dividing randomly the 54 fresh female students from the University of Bisha into two equal groups: the experimental group and the control group. The selection was based on their achievement in First Exam. To measure students' acquisition of the derivative concept, the researchers relied on a post-test, and semi-structured interview with some learners. The analysis of the obtained data showed that teaching Calculus using Flipped Classroom Strategy that based on Critical Thinking Skills is better than the traditional teaching methodology in the acquisition derivative concept. In fact, the interviews show that the fresh female students in the experimental group preferred the new strategy, and said that it makes learning mathematics interesting and easier.
\end{abstract}

Keywords: flipped class room, critical thinking skills, acquisition of derivative concept, calculus, blackboard

\section{INTRODUCTION}

Calculus is one of the most important branches in the beginning of the study of Mathematics. It is also used in many scientific, engineering, administrative, economic, and health disciplines. Calculus is a fundamental course that students must pass to study advanced courses. Yet, Bressoud, Ghedamsi, Martinez-Luaces, and TÖrner (2016); Denbel (2015); Muzangwa and Chifamba (2012); and Uygur and Ozdas (2005) asserted that students suffer many difficulties in their studying of calculus.

Concerning the difficulties students face in studying the Calculus course, Muzangwa and Chifamba (2012) stated that they were making conceptual errors when studying

Citation: Al-Zoubi, A. M., \& Suleiman, L. M. (2021). Flipped Classroom Strategy Based on Critical Thinking Skills: Helping Fresh Female Students Acquiring Derivative Concept. International Journal of Instruction, 14(2), 791-810. https://doi.org/10.29333/iji.2021.14244a 
Calculus. This was due to the gaps in basic algebraic knowledge and to the weakness of their advanced thinking. El-khateeb (2015) also emphasized that most of the students failed during their education because of their weak perceptual structure of basic conceptual requirements, which are necessary to study new mathematical topics, such as the concept of limit, continuity, derivative and other concepts in Calculus.

The derivative concept is a difficult concept for many students. Uygur and Ozdas (2005) asserted that there was a lack of awareness of the derivative concept as a rate of change. They further explained other weaknesses in derivative concept, when the function considered was a composite function. Farther more, students focus more on symbolic rather than graphical derivative representation in learning a concept. They also lack making logical connection between these kinds of representations, and weakness of dealing with generalized questions (Denbel, 2015). In addition, Mehrage and wahge (2016) stated the difference between the description of a derivative concept (describing the slope of a tangent line at point on the curve) and the formal concept definition of the derivative of a function on a particular point.

Most of the studies suggested that those difficulties in acquiring derivative concept were because of the teaching implication. Tall (1992) concluded that the most of teachers are often attempt to circumvent the problems by using an informal approach playing down the technicalities. Eichler and Erens' (2015) showed that the teachers focused on instrumentalist view of teaching Calculus; as the set of rules and procedures preserved and applied in routine tasks, which prepare students for the final test. They did not show any interest in the role of technology. On the other hand, studies described some procedures to fix the situation as Mehrage and wahge (2016) stated that the teaching implication should focus on representations and relevant connections as part of understanding a derivative concept. As Siyepu (2015) asserted that the identification of errors might assist lecturers and mathematics teachers to focus on the development of pedagogical techniques that may overcome students' difficulties in their learning of derivative concept.

Researches, have demonstrated the impact of technology on teaching and learning calculus. Bressoud, and et al. (2016); Buch and Warren (2017); and Jaradat (2018) have shown the technology strength in improving the visualization skills of forming visual mental images, with a focus on the relationship between intuitive and formal ideas in teaching and learning Calculus concepts through the visual approach . Vinner (1991) has defined the conceptual understanding as an image of a concept that forms and corresponds to the definition (abstract term). He explained that cognitive structure is associated with the concept and includes all mental images and characteristics and processes associated with it. It also includes conceptual and procedural knowledge of how to deal with the situation. Maharaj and Wagh (2016) pointed out that building a conceptual structure in mathematics must be structured and logical to students, who should be taught mathematics for relational understanding of the mathematical concepts of Calculus.

Accordingly, the Conference Board of the Mathematical Sciences (CBMS, 2016) recommended that the higher education institutions in general, and mathematics 
department faculties in particular, should integrate active learning in classrooms based on integration between science, technology, engineering, and mathematics; and need to be well informed about active learning and related topics. Braun, Bremser, Duval, Lockwood, and White (2017) urged teachers, universities and colleges to work hard to train the next generation of mathematicians by finding better ways to teach mathematics. These ways should be effective and motivational in order to make students work hard, love learning, accept the challenge of finding solutions to problems, and use "active learning techniques" that focus on students and engage them in various activities, such as reading and writing, discussing, and problem solving, which in turn enhance students' higher-order thinking skills.

The importance of teaching mathematics at university appears from researches that have shown a low level of achievement for undergraduate students (Akgün \& et al., 2010, CBMS, 2016), as well as in Saudi Arabia (Al-Hujaili, 2011; Al-Saadawi, 2017). Several studies as; El-khateeb (2015); Jaradat (2014); Muzangwa \& Chifamba (2012) and Tall (2008) revealed a general weakness in the basic concepts of calculus. This is directly related to the weakness of students' advanced mathematical thinking skills. In particular, when learning in the traditional ways. This happened despite the fact that international university systems urge the use of E-learning in educational systems. These systems rely on informational mechanisms to manage education, monitor students, and supervise the efficiency of the educational process such as the Blackboard system. It provides students with great opportunities to communicate with the course outside the lecture hall anywhere and anytime. This is done through an electronic system that provides them with various tools to view the content of the course material and interact with it in an accessible way. In addition, it also allows the students to communicate with the course teacher and the other students registered in the course by various electronic ways. It consists of tools and methods that allow faculty members to build dynamic and interactive courses with great facility while managing the content of these courses in a flexible and simple way. This makes the daily tasks of the educational process more effective by taking advantage of the classroom time to complete tasks that depend on developing (HOTS) among students, and to develop conceptualization in Calculus.

In light of this, the participants in the third annual meeting of university teaching that was held at King Saud University from 4-7 April 2016 also confirmed on the necessity of employing educational technologies through blended learning, the most prominent of which is the flipped classroom. Studies by Buch and Warren (2017); Carter, Carter and Fos (2018); Hart, Daucourt and Ganley (2017); Renfro (2014); Sahin, Cavlazoglu and Zeytuncu (2015); Zengin (2017) have shown a positive effect on students' achievements in the Calculus course when applying the Flipped Classroom Strategy (FCS). Other researchers studied the effect of this strategy on other mathematics courses (Khan and Watson, 2018; Ramaglia, 2015). All of these studies focused on general achievement and neglected acquiring and understanding specific concepts in mathematics, such as the derivative concept, which is the goal of our study. 


\section{Theoretical Framework}

Flipped Classroom (FCS) is an educational model in which the lecture mode and homework assignments are overturned. This happened when short video lectures are prepared for students to watch at home before the actual lecture time while the classroom is only devoted to exercises, projects, or discussions. Lectures outside the class are under the control of students, who can watch, rewind and accelerate forward as required. The real value of the (FCS) is to allocate class time for students' work in doing research, discussion, questions, and class interaction. This gives the teacher an opportunity to reveal the students' thinking errors. The teachers' role is a trainer, facilitator, consultant, and student promoter in achieving individual and group achievements. The students themselves are able to manage their thinking (Brame, 2013; Buch \& Warren, 2017; EDUCAUSE, 2012).

Ryerson University Learning and Teaching Office (2013) added that (FCS) was a type of integrated learning based on a constructive learning model that focuses on individual thinking of student, making them more active. The role of the teacher as a trainer, facilitator, motivator, and student-oriented, inside and outside the classroom. EDUCAUSE (2012) has clarified that the teacher has a role in preparing and supervising video lectures and audio recordings, and it is possible to use files and presentations from educational sites in the (FCS). For example, Zengin in one of his studies (2017) applied the (FCS) designed for using free open source mathematics programs in Khan Academy. He applied it to students in the mathematics department of a public university in Turkey

Braun and et al. (2017) said that the nature of pre-class presentation includes basic definitions, examples, proofs, and reasoning. Class time is available for active learning tasks that depend on the type of task used during at the time of the lecture. The students are merged into either think-pair-shares if the task is complex. Or small groups to complete assignments and worksheets, which aim to get students to recognize logical mathematical arguments, and then communicate their mathematical ideas clearly and consistently orally or in writing, while working creatively, achieving self-efficacy, creating and exploring examples conducting mathematical experiments, evaluating the correctness of solutions, innovation and conjecture.

Educational literature provides different models for the practice of (FCS), giving the teacher the opportunity to behave in the steps of the strategy commensurate with the learning environment and the nature of students. The strategy can be integrated with other teaching strategies. Strayer, Hart, and Bleiler -Baxter (2016) identified three criteria in the complementation of (FCS) which are not necessarily in order; but depend on the situation. The first criterion is (outside the class) using assignments to motivate, meditate and provoke students to respond. The second criterion (within the class) also uses the tasks to build new knowledge that students need in the future. The third criterion is to link the assignments within and outside the classroom through the teaching method itself. 
Several studies focused on the effect of (FCS); Renfro (2014) showed that the (FCS) was a comprehensive educational strategy that focused on students to become lifelong learners. It affected positively the students' achievement and their mathematical reasoning in Calculus. However, Ramaglia (2015) found that there was no difference between the study group averages in achievement, or improvement in students' perceptions of their mathematical abilities to encourage them to study future mathematics courses. As for the university students themselves, they prefer to watch educational videos when applying the strategy compared with reading texts, and this has affected students' achievement positively (Sahin, Cavlazoglu \& Zeytuncu, 2015).

The goal of this strategy is not only to cover the scientific content, but also to help students to perform well in mathematics, especially in courses where students face difficulties such as in Calculus. Tall (2008) confirmed that freshmen in Calculus must transition their thinking towards a formal framework of intuitive thinking and mathematical proof. However, Dane, Çetin, Baş \& Sağırlı (2016) have made it clear that demonstrating the hierarchical structure between calculus concepts is a difficulty that students usually face because their learning depends on mastering the procedural knowledge related to these concepts, and use of the algorithms without connecting them to their conceptual knowledge theoretically. Zengin (2017) pointed that the (FCS) contributed to developing the conceptual understanding of students in mathematics. This appeared through their better acquisition of concepts, and the formation of clear mental image of concepts, in helping them to raise their ability to retain information, and in making understanding much easier.

Although the acquisition of concepts represents a large part of the classroom learning process, it must be an active process for students interaction to develop their understanding and learning to be meaningful. It should be noted that students who do not master the basic concepts would face many problems in learning new topics in advanced levels (Abbas \& Al-Absi, 2007; Muzangwa \& Chifamba, 2012; El-khateeb, 2015). Gordon and Gordon (2006) stressed to use realistic contextual' examples and problems and to force the students to think, not just to manipulate symbols in all steps of teaching and learning Calculus. Dane \& et al. (2016) recommended that the teacher provide tasks for students to help them connect between their conceptual and procedural knowledge, and their acquisition of the concepts learned in the calculus.

The conducted researches asserted that the kinds of tasks applied in Calculus situations in class like examples, homework assignments, and all other projects must focus on conceptual understanding. As Maharaj and Wagh (2016) recommended the application of tasks based on Higher-Order Thinking Skills (HOTS) to help students during studying Calculus to focus on understanding and interpreting mathematical definitions, translating a problem verbally formulated or graphically represented to the formal mathematics. These tasks also identify the possible applications of mathematics in reality, and focus on identifying the links between sets of concepts and interpreting these links in mental schemes, working regularly from special cases to the general formula, and focusing on a critical assessment of other solutions. It also includes the interpretation and expansion of task solutions, using it to develop reasonable skills in the 
context of mathematical exploration. Several educational studies indicated in the (HOTS) have many patterns of thinking; such as critical thinking, creative thinking, and reflective thinking. They have identified that the critical thinking skills are the most important skills university students need to develop (Al-Bajalani, 2019; Alzahrani, 2016; McGregor, 2007). Critical thinking is not specified to an age, as it is one of the methods of thinking that the person acquires through exercise and training and has no natural instinct (Al-ostath, 2013).

Critical thinking gives the students to think independently, formulate his own opinions, draw conclusions based on systematic analysis, and see the relationships between ideas (Crockett, 2017). It includes a number of skills referred to by both Obaid and Afaneh (2003). Such skills are the prediction of assumptions, which is enables the individual to define assumptions that serve as a solution to a problem or opinion on the issue at hand. The skill of deduction that is intellectual ability to use his knowledge and data to distinguish between validity of the outcome or error in relation to the facts given. The skill of evaluating the discussion that is the individual's ability to distinguish between strengths and weaknesses to judging an issue or incident in the light of the evidence given. The skill of interpretation which is the ability of individuals to interpret the situation as a whole and give justifications to draw a particular result in the light of the facts given that are accepted by the mind. Both authors added that employing these skills is important in learning mathematics

On that context, the students should be able to change their thinking in divergent ways. They must show the conceptual understanding and the meaning of mathematics, by realizing the hierarchical structure in Calculus concepts, and employing their conceptual knowledge and their procedural knowledge together to expand their knowledge. Tall's theory of the Three Worlds of Mathematics (TWM) explored the mechanism of conceptualization in Calculus (Tall, 2008). This mechanism has three stages as a mathematical model. The first one is the Conceptual-embodied in which the mental conception is constructed based on the characteristics of things. In this particular stage there is a significant impact of contemporary technology in building a clear and close conception of the concept that allows the generation of drawings corresponding to the nature of the functions used in Calculus and the possibility of making changes that illustrate the examples of the concept of derivative. At the outset, it has a structural image as a slop to function with the help of computer programs. The second stage is Proceptual-symbolic. The concept is used within its symbolic form through the application of "Process" and thinking of "Conceptual". This phase is linked to the previous stage where the relationship between the symbolic and graphical helps to form a clear conceptualization of the concepts of Calculus. Therefore, we use the symbols of derivation to deal with the image of the concept and clarify its characteristics. The third stage is Formal-axiomatic; where the sequence in the construction of meaningful concepts in a formal form is based on definitions of known objects and the use of proven definitions of abstract theory. At this last stage we use the limit as a prior knowledge to define the formal concept of the derivative (Tall, 2008). 
The practical application of (TWM) appears by using (FCS) at all stages (Bram, 2013; Strayer \& et al., 2016; Tall, 2006). First, the mental conception is constructed outsaid of the classroom and technology is an effective factor in these stages, although it does not require a high level of technicity (Bram, 2013). Strayer and others (2016) emphasised the use of assignments in this stage. These stages motivate students to think of the characteristics of concepts and encourage them to search and investigate in the image of concept. In the second phase within classroom, students will recognize the different ways of expressing the concept by using the tasks to build relationships between the symbols and the wording of the term or the rules and describe the dynamics of the concept (Tall, 2008). These tasks apply based on (HOTS) to help students follow the assumptions in the task to reach known results from the concept as the classification between validity of the outcome or error in relation to the facts given and focus on understanding and interpreting mathematical definitions. These tasks also help students to build new knowledge implemented in the future (Maharaj \& Wagh, 2016; Strayer \& et al., 2016). The third phase concentrate on the relationship between assignments and tasks for the construction of meaningful concepts in a formal form based on definitions of known objects, and show the conceptual structure (Tall, 2008). Comprehension tests apply to assess the extent of students' acquisition of the Calculus concepts which are based on asking step-by-step questions to help teacher define concept mistakes that students commit, and at the same time ensure that the definition of the concept is formed correctly (Akgün, Isleyen, Tatar, Soylu, \& Duru, 2010). Meanwhile, tests that focus on procedural knowledge show that students tend to memorize concepts without thinking or understanding (Dane \& et al., 2016; Tall, 2008).

Our study found that there was an imbalance in the acquisition of the derivative concepts of a Calculus course for students of the first university stage (Denbel, 2015; Vincent, 2016). It also found that there was imbalance in the ability to employ learned thinking skills (Al-Bajalani, 2019; Alzahrani, 2016). It also found that teaching at the university level was still largely dependent on the traditional lectures according to the researchers' experience of teaching Calculus despite the increasing number of studies on the use of the (FCS) verified that they had a big impact on students' learning Calculus (Buch \& Warren, 2017; Hart \& et al., 2017; Renfro 2014). The researchers are convinced that there is a necessity to update university teaching strategies to the current developments based on integrating technology and implementing it in the educational process. The researchers employed the (FCS) while teaching the Calculus course to be based on the application of critical thinking skills (CTS) in the Flipped Classroom Strategy based on Critical Thinking Skills (FCSCTS) and they explored the effectiveness of this new compound strategy at undergraduate students. Therefore, these are the research questions that we sought answers to:

1. Does this strategy help fresh female students to prepare in advance of the lecture?

2. Are there statistically significant differences between the means of the test of acquiring the derivative concepts (total) among fresh female students due to this teaching strategy? 
3. Are there statistically significant differences between the means of the capabilities of acquiring the derivative concepts (understanding and comprehension, and transfer) among fresh female students due to the teaching strategy?

4. How the fresh female students demonstrated their acquisition of the Derivative concept?

\section{Significance of the Study}

The importance of the study lies that this proposed strategy comes to keep pace with the trends of higher education in universities that call for the need to activate modern strategies by integrating modern technologies in education, and they encourage students to activate critical thinking skills. In addition, the study may help open horizons for educators researchers to conduct similar research accordingly to the scarcity of studies on the use of this strategy in the scientific fields in the Arab world, which may enrich educational library .

The study would play a fundamental role in the application of students' critical thinking skills while studying the calculus course. It could lead to students' support in building and designing realistic experiences through the practice of critical thinking, as developing and improving thinking have become the focus of most recent studies.

\section{METHOD}

\section{Participant}

The sample comprised of 54 fresh female students, who were studying Math 101Mathematics (I) course during the implementation of the study, it is a typical first-level mathematics unit, covering Functions, Limit, Continuity and Derivation, during the Spring 2018 semester in a Faculty of Science and Arts in Al Namas- Bisha University; in the Kingdom of Saudi Arabia. The participants were randomly distributed into twosample groups; each group consisted of 27 fresh female students. Then the parity of the two- sample groups was verified by analysing the results of the achievement test (First Exam); which is the first period test prepared by the educational institution in the course of Math 101. The test was given to all fresh university students studying that course. The final mark allotted to the test was 20 points. The first group learned through (FCSCTS), and the other group learned through (the usual teaching strategy).

\section{Instruments}

We needed to implement a number of instruments in this study. We extracted the statistical reports from the Blackboard system to monitor the percentage of fresh female students preparing for the pre-class lectures. This is to answer the first question, and we used the appropriate statistical analysis test.

In addition, we developed instruments to investigate the effect of the proposed teaching strategy (FCSCTS) on acquiring the derivative concept. Five questions for conceptual understanding of derivation were formulated. These questions were based on the learning outcomes required to be achieved because of studying the course. We used previous studies in designing the questions that measure the acquisition of derivative 
concept. For example, we made use of the following studies: Oehrtman, (2008); Muzangwa \& Chifamba, (2012); Renfro, (2014); Denbel, (2015); Vincent, (2016). The items were prepared to measure two of capabilities of students. The first capability is understanding and comprehension, which is the ability to know the concepts and the examples that apply to these concepts. This capability include three criteria, which describe the expected learning outcomes from the use of the strategy, these criteria are recognition, proving and disapproving, and inference. The other capability is transfer, which is the ability to expand knowledge by finding more connections in the conceptual structure, it include two criteria to describe expected learning outcomes from the use of the strategy, these criteria are translation, and connection (see Appendix 1). We verified the psychometric properties of the exam before applying it to the sample.

We applied an additional instrument to interpret our quantitative findings from the learners' responses in the exam "semi-structured Interview", which consisted of open questions. These questions made fresh female students demonstrate their capabilities and criteria from acquiring the derivative concept. In addition, how they are affected by the teaching strategy used, and identify the obstacles that the fresh female students faced while applying the strategy in the studied groups.

\section{Procedure}

Four weeks were spent with the experimental group and five weeks with the control group. We observed three lectures to teach the concept of derivatives. Thirteen videos on Blackboard were used with the experimental group. On other group, we spent five lectures, and thirteen text presentations on Blackboard were used to teach the same concept. We followed the statistics reports, which was extracted from Blackboard. The statistics reports appeared fresh female students' percentage; they were attending lectures before class time.

A conceptual acquisition test was applied after teaching the groups the derivative concept. The test papers were collected from the study groups and then corrected and tabulated by SPSS. To measure the effect of the proposed teaching strategy namely (FCSCTS) on acquiring the derivative concepts, the Covariance test (ANCOVA) was used to remove the effect of any untested variables. The Multivariate Analysis of Variance (MANOVA) was used to compare between the two mean of the groups' capabilities; understanding, comprehension, and transfer.

The quantitative data was collected first, followed by qualitative data. Qualitative data were generated from the semi-structured interviews with six randomly selected fresh female students who were chosen to participate in the interviews to make sense of the difficulties learners encountered in this study. This study followed an explanatory sequential mixed-methods design in which quantitative data informed qualitative data (Creswell, 2014).

\section{FINDINGS AND DISCUSSION}

When analyzing the results of the statistical reports of fresh female students attending the lectures before its time, we found that $87 \%$ of the fresh females in experimental group followed the lectures on the site. On the other hand, the rate' students of the 
control group did not exceed $11 \%$, as they depended greatly on professors in displaying educational content. The students of the experimental group have shown interaction and integration in the educational process in terms of knowledge and advance preparation. It was found that video' lectures included; basic definitions, examples, proofs, and reasoning in an attractive display with thoughtful techniques, that could help fresh female students prepare in advance of the lecture time, but the use of textual preparations made it difficult and boring for students in the control group to make a greater effort to understand.

That results matched the claim of Brame (2013); EDUCAUSE (2012); Sahin, Cavlazoglu and Zeytuncu (2015); Strayer and et al. (2016), that the strategy pushed and prepared the students to apply what they learned, and it was an incentive for them to determine, strive and persevere. In our study; The (FCSCTS) helped learners to construct the mental image of derivation concept by implementation video lectures and assignments outside of the classroom. This stage called Conceptual- embodied in Tall's theory TWM (Tall, 2008). It encourage students to search and investigate the image of concept. This data were collected to answer the first question.

To answer other study questions, the data collected from the developing instrument were analysed by using (ANCOVA) to ensure that the study results were not affected by the student's pre-achievement level in First-exam. The results showed that there was one significant difference between the groups regarding to the teaching strategy in the acquisition the derivative concept, as table (1) shows:

Table 1

ANCOVA test for acquisition the derivative concept (total)

\begin{tabular}{llllll}
\hline Source & Type III Sum of Squares & df & Mean Square & F & Sig. \\
\hline First-exam & 5.089 & 1 & 5.089 & .408 & .526 \\
\hline Teaching strategy & 165.128 & 1 & 165.128 & 13.259 & .001 \\
\hline Error & 635.518 & 51 & 12.461 & & \\
\hline Corrected Total & 800.759 & 53 & & & \\
\hline
\end{tabular}

The Eta square $\left(\lambda^{2}\right)$ was calculated to determine the effect size of the teaching strategy, the result indicated that $20 \%$ of the total variance in the test scores for the acquisition of the derivative concept between the two groups was due to the teaching strategy used. As figure (1) shows the number of fresh female students would try to solve questions; that show the variance between groups acquired the derivative concept. The capability of understanding and comprehension appeared more than the capability of transfer. In the attempts of the fresh female students on the questions $(1,2,3)$, they achieved higher level than the students' attempts to the questions $(4,5)$ in experimental group.

This is consistent with the result shown in Table (2). It was found that the mean performance of fresh females on the questions about the ability to understand and comprehend (6.06), which was higher than the mean of fresh female ability to transfer as it reached (3.46). The overall higher performance was in favour of the fresh females of the experimental group.

The findings were matched the findings of the following authors; Buch and Warren (2017), Carter and Fos (2018), Hart, Daucourt, and Ganley (2017), Renfro ( 2014), 
Sahin, Cavlazoglu, and Zeytuncu (2015) who suggested that the strategy of (FCS) has a positive impact on the achievement of students in general. The strategy has also improved the conceptual understanding of students in mathematics as (Khan and Watson, 2018; Zengin, 2017). This conceptual understanding included with mental image of concepts and the characteristics of the processes associated with it (Vinner, 1991).

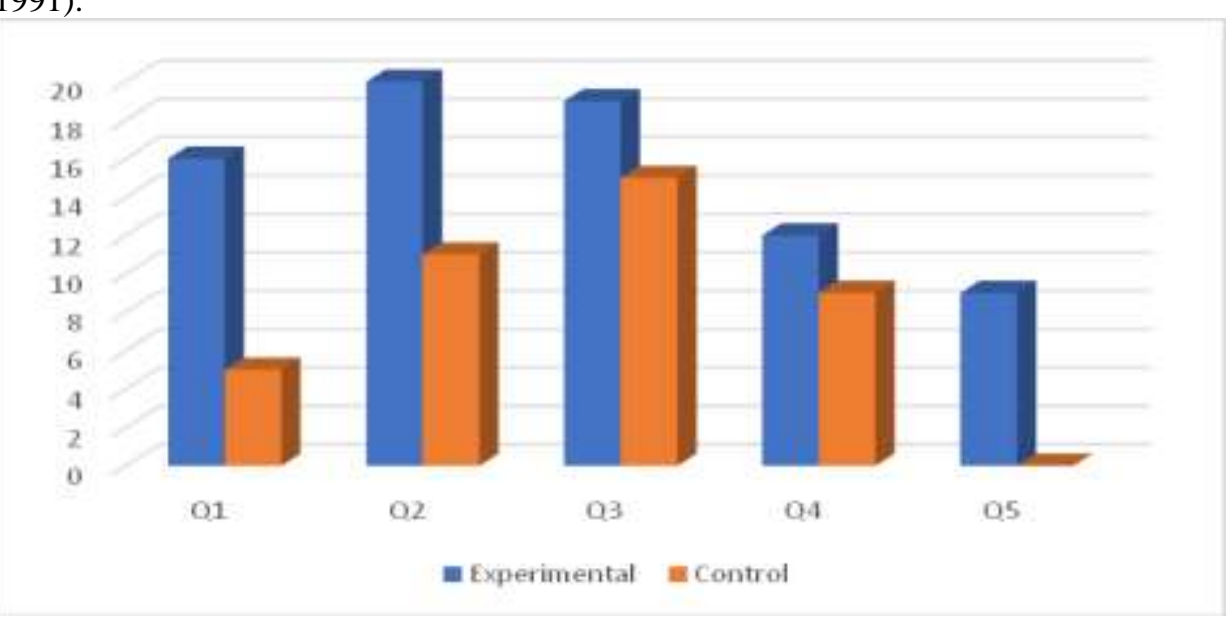

Figure 1

The number of fresh female students trying to solve questions

The (FCSCTS) made students recognize the different ways of expressing concepts by using the tasks to build relationships between the symbols and the wording of the term or the rules and describe the dynamics of the concept. It was found that the group that implemented the (FCSCTS) has achieved positive results in the derivative concept acquisition test including capabilities (Understanding \& Comprehension, and Transfer).

Table 2

Descriptive statistics for acquisition concept of the derivative (total+ capability)

\begin{tabular}{llllll}
\hline & Dependent variables & Teaching strategy & Mean & Std. Deviation & N \\
\hline \multirow{3}{*}{ Concept } & \multirow{2}{*}{ Derivative* } & Experimental & 9.52 & 4.061 & 27 \\
& & Control & 5.07 & 2.854 & 27 \\
& & Total & 7.80 & 3.887 & 54 \\
\hline \multirow{4}{*}{ Capability } & Understanding \& & Experimental & 6.06 & 2.276 & 27 \\
& Comprehension & Control & 3.33 & 2.253 & 27 \\
& & Total & 4.94 & 2.508 & 54 \\
\cline { 2 - 5 } & \multirow{2}{*}{ Transfer } & Experimental & 3.46 & 2.457 & 27 \\
& & Control & 1.74 & 1.130 & 27 \\
& *maximum mark =20 & Total & & & \\
\hline
\end{tabular}

To demonstrate the significance of the statistical differences that appeared between the means related to the capabilities of acquiring derivative concept, (MANOVA) test was used, as shown in Table (3). 
Table 3

MANOVA test for capabilities of acquisition derivative concept

\begin{tabular}{llllllll}
\hline Source & Dependent variable & $\begin{array}{l}\text { Type III Sum } \\
\text { of Squares }\end{array}$ & df & $\begin{array}{l}\text { Mean } \\
\text { Square }\end{array}$ & F & Sig. & $\begin{array}{l}\text { Partial Eta } \\
\text { Squared }\end{array}$ \\
\hline Teaching & Understanding \& Comprehension & 66.667 & 1 & 66.667 & 13.00 & .001 & 0.200 \\
strategy & Transfer & 20.167 & 1 & 20.167 & 5.515 & .023 & 0.096 \\
\hline \multirow{2}{*}{ Error } & Understanding \& Comprehension & 266.667 & 52 & 5.128 & & & \\
& Transfer & 190.148 & 52 & 3.657 & & & \\
\hline Corrected & Understanding \& Comprehension & 800.759 & 53 & & & & \\
Total & Transfer & 210.315 & 53 & & & & \\
\hline
\end{tabular}

Table (3) shows that there are positive statistically significant differences at the level of statistical significance $(\alpha=0.05)$ in the capabilities of the acquisition of the derivative concept attributable to the effect of the teaching strategy, while the practical significance $\left(\lambda^{2}\right)$ showed $20 \%$ of the variance between the study groups in the ability of understanding and comprehension. This was because of the teaching strategy that reflects the strong influence of the (FCSCTS) on the acquisition of fresh female students in the ability to recognize concepts and applicable examples. As Tall (2008) described it in the second stage of his theory TWM, which he called the Proceptual-symbolic, where the tasks used to build the relationship between the different representations of concept, and to form a clear conceptualization of concepts Calculus. That result coincided with the Maharaj \& Wagh's (2016) study in the application of tasks that rely on higher thinking skills that helped students to develop their understanding of calculus.

To clarify the difference in the ratio of variance between the understanding \& comprehension capability of acquiring the derivative concept between groups, we examined the effect size of the teaching strategy (FCSCTS) on the constituent criteria for its capacity shown in Table (4), which shows the values of the practical significance of the teaching strategy for each criterion. The percentage of variance between the groups in the criterion for the proving and disproving was the highest, $(13.9 \%)$ of the variance between fresh female students in following the assumptions in the task to reach known results from the concept to give an example or not. This was due to the teaching strategy (FCSCTS). Then the percentage of variance between groups in the criterion of the Inference was $12.7 \%$ of the variance between fresh female students in formulating the general definition and determining the distinctive characteristics of the concept was due to the teaching strategy (FCSCTS). These variances between groups demonstrate the ability of students in experimental group to use logical structure among Calculus concepts that students need to build conceptual structure relationally (Maharaj \& Wagh's, 2016). However, 5\% of the percentage of variance between groups in the criterion of recognition. This means that the performance of fresh female students in both groups was close about this question. The fresh female students could distinguish between the ways of expressing of the derivative concept; whether by symbols, or the wording of the term and the rules, or by describing the dynamics of the concept. As an example the lack of awareness of the derivative concept as a rate of change (Uygur \& Ozdas, 2005) the fresh female students in experimental group described the dynamics of concept in this question. 
On other hand, the results of the practical significance $\left(\lambda^{2}\right)$ of the transfer ability in the acquisition of fresh female students in the derivative concept showed $9 \%$ of the variance between the study groups due to the teaching strategy used. The experimental group students demonstrated a greater ability to expand knowledge by finding more links in the conceptual structure than students of the control group. This result was accepted but not satisfactory. Therefore, the semi-structured interviews were conducted with six fresh female students, who revealed that their total scores were less than the group's mean scores on a derivative concept test in two groups. During the interview fresh female students hesitated to answer, and some students from the control group refused to answer. The students of the experimental group hesitated at first, and then showed their knowledge of derivative concept. They accepted the challenge to search the solutions for problems, which suggest the use of active learning techniques with university students contributed them to better learning. It encouraged them to strive, and love learning (Braun \& et al., 2017).

Extract 1: Student 3 (from control group) Semi-structured interview

Researcher: How do you represent the derivative concept of function on the following drawing?

Student 3: (Low voice) I don't know how to paint !!

Researcher: How do you see this concept on the drawing itself?

Student 3: (After waiting 3 minutes for her to talk about drawing) "I don't know how to express my idea."

Researcher: Just clarifying the concept?

Student 3: If you would allow me. I would not like to speak.

Extract 2: Student 4 (from experimental group) Semi-structured interview

Researcher: How do you represent the derivative concept of function on the following drawing?

Student 4: You mean, should me draw?

Researcher: No, On this drawing, where do you see the concepts? Can you explain?

Student "4": If we move from the right to this point, the function takes negative values, while from the left the values are positive, because they are not equal, so the Limit is not there. And because the limit is not exist at this point, it's discontinuous, "Originally it is clear from the drawing that it is in a jump here (she pointed at $(-2)$ ), while the function is continuous throughout the interval....(she still talked) To find the derivative.... we have a constant function hear, so the derivative is zero, (she referred in the period $[-2,2]$ ), but if you want for me find that (she pointed the drawing in $[2, \infty)$ ), you must give me a rule for that function.

Researcher: No, I do not have it..!!!

Student 4: Ok, I will try now. I know that "Velocity" is a derivative.

Researcher: So what!!

Student 4: I need to draw some line, it seems a velocity.

Researcher: Can you explain more?

The response of student "4" indicated her intellectual ability to interpret the situation as a whole and give justifications to draw a particular result in the light of the facts given that are accepted by the mind, which suggests that the application of tasks based on Higher-Order Thinking Skills (HOTS) help students during studying Calculus to focus 
on understanding and interpreting mathematical definitions, translating a graphically represented problem to the formal mathematics (Maharaj \& Wagh, 2016).

Table (4) shows that (FCSCTS) influenced the attainment of the criterion of connection, i.e. identifying the links between concepts and their interpretation, and showing the conceptual structure, where the percentage of variance between groups reached 15\% according to the values of practical significance $\left(\lambda^{2}\right)$. The strategy helped choosing assignments that depend on linking concepts and employing previous knowledge has led fresh female students to form connections between the concepts of Calculus. There was no distinctive effect of the strategy on fresh female students' acquisition of the criterion of translation, which use various mathematical representations that are relevant to the concept.

Table 4

The practical effect of (FCSCTS) on criteria's capability

\begin{tabular}{lll}
\hline Capability & Criteria & Partial eta square \\
\hline \multirow{2}{*}{ Understanding \& } & Q1: Inference & $12.7 \%$ \\
Comprehension & Q2: Proving \& disproving & $13.9 \%$ \\
\multirow{2}{*}{ Transfer } & Q3: Recognition & $5.1 \%$ \\
\cline { 2 - 3 } & Q4: Translate & $2.8 \%$ \\
& Q5: Connect & $15.5 \%$ \\
\hline
\end{tabular}

During the interview, all students in control group showed difficulties to deal with the drawings, and they mentioned that they are not acquainted with the rules of function "symbolic representation", which suggests that learners lacked making logical connection between symbolic and graphical derivative representation (Denbel, 2015; Elkhateeb, 2015). However, the fresh female students in experimental group showed various representations as regards of the derivative concept in drawing. The two examples below represent the responses during interview:

Example (1): The derivative as the slop of line.

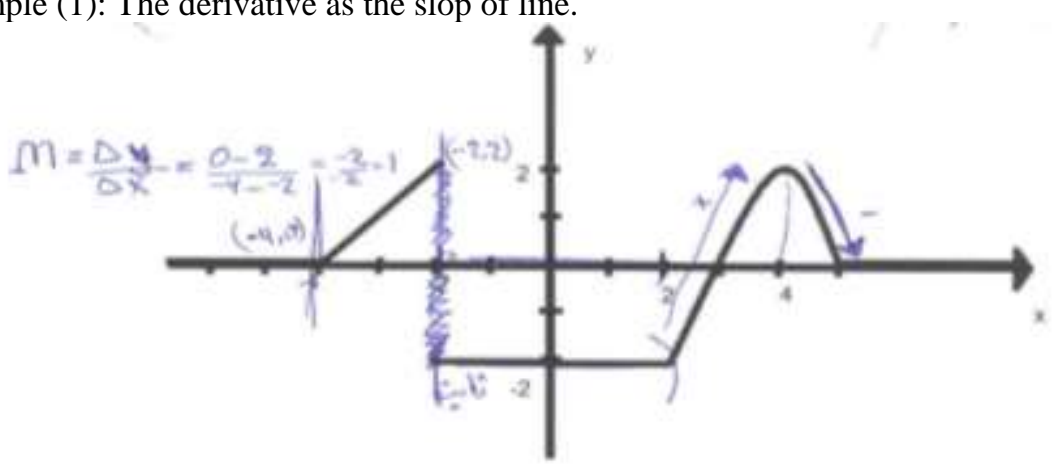

Example (1) shows the derivative as the slop of line by using the rate of change between two point on the line. Example (2) uses the characteristics of critcal point on function, and connects with the slop of tangent line at the same point. The fresh female students show the conceptual understanding and the meaning of derivative, by realizing the 
hierarchical structure in Calculus concepts, and employing their conceptual knowledge and their procedural knowledge together. It seems the nature of examples and tasks applied in (FCSCTS) helped fresh female students to expand their knowledge, and they used various representations of derivative concept. This result matched Al-Juhani and Muwafi (2018) study that the flipped class has an impact on the development of the skill of mathematical representation among students.

In addtion, the fresh female students were excited with the strategy by creating mental images of concepts before the time of the classroom lecture. Adjusting these images through the tasks that students were assigned to accomplish before the classroom lecture. Those tasks require the use of their previous conceptual and procedural knowledge learned through the learning site of Blackboard. Video lectures allowed students to repeat them in unlimited number of times, and can be followed up at any time that suits them as referred to by Brame (2013); EDUCAUSE (2012) Strayer, and et al. (2016). In addition, providing the appropriate feedback to try to correct the errors committed by fresh female students before the time of the classroom lecture was positively reflected in the classroom lecture. This is because the fresh female students avoided repeating the same mistakes, and corrected one another during their group work. This made the learning process active towards the completion of the required tasks. Their eagerness to participate in class increased (See Braun, \& et al., 2017; Khan \& Watson, 2018).

Example (2): The derivative at critical point $=0$.

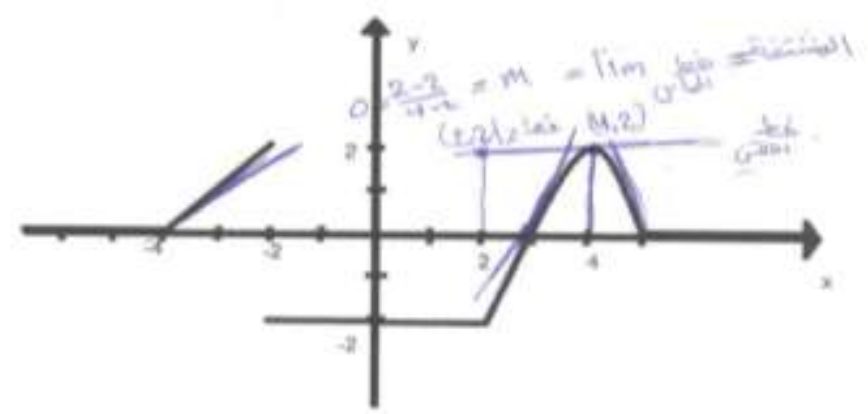

\section{CONCLUSION}

The study demonstrated the importance of teaching university students whos are future teachers using the (FCSCTS). It changed the culture of teaching and learning for undergraduate students and their teachers. It redistributed the roles between them and made the students focus of the university educational learning process. They focused on the efforts made by students to improve their understanding and develop their capabilities in a positive way. This can be through including this strategy in other subjects of mathematics and in other courses. This will enable students to use their intellectual and mental activities in achieving goals that facilitate the learning process, 
make it meaningful, and contribute to the future in using the knowledge they have acquired positively.

The strategy also increased the participation of fresh female students by enhancing their positive interaction with their classmates, and made class discussions more effective and fruitful. They assessed their ability to establish social relationships in the classroom lecture at a high level. This change was reflected in their acquisition of the concepts of Calculus. They achieved a high level of ability to acquire the derivative concept. It is suggested that more studies should be conducted to investigate the effect of the (FCSCTS) on various topics in mathematics, at different levels and variables.

\section{ACKNOWLEDGEMENTS}

The authors would like to acknowledge the support of the Vice Presidency for Graduate Studies and Scientific Research in the University of Bisha (58/38/16965) Date: $12 / 6 / 1439 \mathrm{H}$.

\section{REFERENCES}

Abbas, M., \& al-Absi, M. (2007). Curricula and methods of teaching mathematics for the lower basic stage. Jordan, Dar Al-Masirah

Akgün, L., Isleyen, T., Tatar, E. Soylu, Y., \& Duru, A. (2010). Comprehension test in calculus course. Procedia Social and Behavioral Sciences. 2, 1527-1531. http://www.sciencedirect.com.

Al-Bajalani, F. (2019). Teaching "Academic Debate and Critical Thinking" to Undergraduates in Kurdistan of Iraq. Conference Paper: Challenges and Prospects, At University of Salford, Manchester. https://www.researchgate.net/publication/331481669

Al-Hujaili, M. A. (2011). The effect of teaching mathematical concepts using the problem-centered learning strategy on achievement and the trend towards mathematics among new students in the mathematics department of the Teachers College in Madinah. Reading and Knowledge Magazine - Egypt, (116), 127-164.

Al-Juhani,M., \& Muwafi, S. (2017). The Effectiveness of Flipped Classroom Strategy in the Development of Mathematical Representation and the Attitude Towards Selflearning Among Second year Intermediate Grade Talented Students in Jeddah. Journal of Mathematics Educations, 20(7) Part 1: 6-45.

Al-Natheer, M. (2004). Proposed Program to Develop Math Teaching for Intermediate School. Dissertation For The Degree Doctor Of Philosophy Of Curriculum And Instruction, College Of Education, The King Saud University, Kingdom of Saudi Arabia.

Alostath, Y. (2010). Effect of using cooperative learning in teaching geography on academic achievement and the development of some critical thinking skills for tenth grade students in North Gaza Governorate. Al-Azhar university, Gaza. 
Al-Saadawi, A. (2017). paper entitled: Levels of Mathematics Graduates on Specialized Teachers' Tests, Fifth Conference on Teaching and Learning Mathematics, King Saud University, Kingdom of Saudi Arabia.

Alzahrani, G. (2016). The Availability of Some Critical Thinking Skills and Their Relationship with Some Variables Concerning The Preparatory Year Students for The Faculty of Sciences and Arts at Makhwah - Al Baha University, KSA. International Journal for Talent Development. 7(13), 155- 176.

Brame, C. (2013). Flipping the classroom. Center for Teaching, Vanderbilt University. Retrieved Sep. 25, 2017 from : http://cft.vanderbilt.edu/guides-sub-pages/flipping-theclassroom/

Braun, B.; Bremser, P.; Duval, A.; Lockwood, E.; \& White, D. (2017).What Does Active Learning Mean For Mathematicians?. Notices of the AMS, 64(2), 124-129. http://www.ams.org/journals/notices/

Bressoud, D.; Ghedamsi, I.; Martinez-Luaces, V.; \& Torner, G. (2016). Teaching and Learning of Calculus. Springer Open, ICME13-Hamburg, Germany. at http://www.springer.com/series/14352.

Buch, G. \& Warren, C. B. (2017). The Flipped Classroom: Implementing Technology To Aid In College Mathematics Student's Success, Contemporary Issues in Education Research, 10( 2 ), 109-116

Carter, C.; Carter, R.; \& Fos, A. (2018). The Flipped Classroom in a Terminal College Mathematics Course for Liberal Arts Students. AERA Open, 4(1), 1-14. http://journals.sagepub.com/home/ero

Conference Board of the Mathemetical Sciences. (2016). Active Learning in PostSecondary Mathematics Education. http://www.cbmsweb.org/Statements/Active_Learning_Statement.pdf.

Crockett, L. (2017). 12 Strong Strategies For Effectively Teaching Critical Thinking Skills. Retrieved Oct 11, 2017. From; https://globaldigitalcitizen.org/12-StrategiesTeaching-Critical-Thinking-Skills

Creswell. J. W. (2014). Research design: qualitative, quantitative, and mixed methods approaches. Singapore: Sage- 4 th ed.

Dane, A.; Çetin1, Ö. F.; Baş, F. \& Sağırl, M. Ö. (2016). A Conceptual and Procedural Research on the Hierarchical Structure of Mathematics Emerging in the Minds of University Students: An Example of Limit-Continuity-Integral-Derivative. International Journal of Higher Education, 5(2), 82 -91.

Denbel, D. (2015). Some Conceptual Difficulties of Students on Derivation. Journal of Educational and Management Studies, 5(4), 211-214. http://www.science-line.com.

EDUCAUSE. (2012). 7 Things You Should Know About Flipped Classroom. Retrieved Sep. 5, 2017 from : http://creativecommons.org/licenses/by-nc-nd/3.0/ educause.edu/el 
Eichler, A. \& Erens, R. (2015). Teachers' Curricular Beliefs Referring To Calculus. In The Use of Technology in Calculus Classrooms - Beliefs of High School Teachers. https://www.researchgate.net/publication/300898232

El-khateeb, M. (2015). Perceptions and Performance of King Saud University Students' about Concept and Finding Limit of Functions Graphical and Symbolic, Journal of Education and Learnin, 4(4), 25-37.

Gordon, F. \& Gordon, S. (2006). What Does Conceptual Understanding Mean?. The AMATYC Review. Memphis, TN, 28(1), 1-18.

Hart, A.; Daucourt, M.; \& Ganley, C. (2017). Individual differences related to college students' course performance in calculus II. Journal of Learning Analytics, 4(2), 129 153. http://dx.doi.org/10.18608/jla.2017.42.11

Jaradat, S.T. (2014). Misconceptions in the Concepts of Limit and Continuity among tht Students of Scientific Disciplines at Yarmouk University. Master Thesis, Yarmouk University.

Jaradat, S.T. (2018). Effectiveness of Web- based Learning Environment on the development of Conceptual Understanding in the Basics of Calculus among the first year University Students. Doctoral Dissertation, Yarmouk University.

Kahn, R. \& Watson, R. (2018). The Flipped Classroom with tutor support: an experience in a level one statistics unit. Journal of University Teaching \& Learning Practice, 15 (3): 1- 19.

Maharaj, A. \& Wagh, V. (2016). Formulating tasks to develop HOTS for first-year calculus based on Brookhart abilities. South African Journal of Science , 112(11/12), 16. http://www.sajs.co.za

McGregor, D. (2007). Development of critical thinking. In : Developing Thinking Developing Learning: A Guide to Thinking Skills In Education. BookEns Ltd, Royston, Herts.

Muzangwa, J. \& Chifamba, P. (2012). Analysis of errors and misconceptions in the learning of calculus by undergraduate students. Acta Didactica Napocensia, 5(2), 1-10.

Obaid, W. \& Afaneh, A. (2003). Thinking and School curriculum. Kuwait, Al Falah Library.

Oehrtman, M. (2008). Layers of Abstraction: Theory and Design for the Instruction of Limit Concepts. Chapter in: Making the Connection: Research and Teaching in Undergraduate Mathematics Education. As A Project Program for Arizona University.

Ramaglia, H. (2015) .The Flipped Mathematics Classroom: A Mixed Methods Study Examining Achievement, Active Learning, And Perception. Dissertation For The Degree Doctor Of Philosophy Of Curriculum And Instruction, College Of Education, Kansas State University, Manhattan, Kansas. 
Renfro, A. (2014). Assessing The Effects Of A Flipped Classroom Approach On Student Achievement, Mathematical Thinking, Attitudes, And Teacher Perceptions In An Undergraduate Calclus Class Using A Participatory Action Research Approach. Dissertation For The Degree Doctor Of Philosophy with a major in Instructional Management and Leadership, Robert Morris University.

Ryerson University Learning \& Teaching Office (2013) • Instructional Design and Research Strategist, Retrieved Sep 5,2017, from : http://www.ryerson.ca/lt

Sahin A., Cavlazoglu, B., \& Zeytuncu, Y. E. (2015). Flipping a College Calculus Course: A Case Study. Educational Technology \& Society, 18(3 ), 142-152.

Siyepu, S. (2015). Analysis of errors in derivatives of trigonometric functions, International Journal of STEM Education (Springer Open Journal), 2-16.

Strayer, J., Hart, J., \& Bleiler-Baxter, S. (2016). Kick-Starting Discussions With the Flipped Classroom. Mathematics Teacher, 109(9), 662-668.

Tall, D. (1992). Published in: Proceedings of Working Group 3 Students' Difficulties in Calculus. ICME-7, Québec, Canada, (1993), 13-28. ISBN 2920916238.

Tall, D. (2008). The Transition to Formal Thinking in Mathematics. Mathematics Education Research Journal, 20(2), 5-24.

Uygur, T., \& Özdaş, A. (2005). Misconceptions and difficulties with the chain rule. The Mathematics Education into the $21^{\text {st }}$ century Project. Malaysia: University of Teknologi. 209-213

Vinner, S. (1991). The Role Of Definitions In The Teaching And Learning Of Mathematics. In Tall, D. Advanced Mathematical Thinking . Kluwer Academic Publishers, Dordrecht, Boston, London.

Vincent , B. (2016). First Semester Calculus Students' Concept Definitions and Concept Images of the Tangent Line and How These Relate to Students' Understandings of the Derivative. Dissertation Degree of Doctor of Philosophy in Mathematics at West Virginia University.

Zengin, Y. (2017). Investigating the Use of the Khan Academy and Mathematics Software with a Flipped Classroom Approach in Mathematics Teaching. Educational Technology \& Society, 20(2), 89-100. 


\section{Appendix 1}

Table 5

Research instrument items

\begin{tabular}{|c|c|c|}
\hline Capability & Include: & Question No. \\
\hline \multirow{4}{*}{$\begin{array}{l}\text { Understanding } \\
\& \\
\text { Comprehensio } \\
\mathrm{n}\end{array}$} & $\begin{array}{l}\text { Inference: Formulate the general } \\
\text { definition and define the distinctive } \\
\text { characteristics of the concept from } \\
\text { others. }\end{array}$ & $\begin{array}{l}\text { Q1: Let } f \text { be the function whose } \\
\text { graph is drawn below. At which } \\
\text { points is } f \text { differentiable? } \\
\text { differentiable to the right? To the } \\
\text { left? }\end{array}$ \\
\hline & & \\
\hline & $\begin{array}{l}\text { Proving and disproving: Follow the } \\
\text { assumptions in the task to reach known } \\
\text { results from the concept (example); and } \\
\text { when any assumptions are not valid } \\
\text { results from the concept (non-example). }\end{array}$ & $\begin{array}{l}\text { Q2: "If a function } f \text { is continuous } \\
\text { at } x_{0} \text {, then } f \text { is differentiable at } \\
x_{0} \text {. Is this statement true? Justify } \\
\text { your answer. }\end{array}$ \\
\hline & $\begin{array}{l}\text { Recognition: Distinguish the different } \\
\text { ways of expressing the concept; } \\
\text { whether by symbols, and the wording of } \\
\text { the term or the rules, and describe the } \\
\text { dynamics of the concept. }\end{array}$ & $\begin{array}{l}\text { Q3: } \frac{\mathrm{dy}}{\mathrm{dx}} \text { is the tangent line that } \\
\text { passes through the point } P\left(x_{0}, f\right. \\
\left.\left(x_{0}\right)\right) \text {. Is that statement true? Explain } \\
\text { your answer. }\end{array}$ \\
\hline \multirow[b]{2}{*}{ Transfer } & $\begin{array}{l}\text { Translate: The use of various } \\
\text { mathematical representations related to } \\
\text { the concept. }\end{array}$ & $\begin{array}{l}\text { Q4: Draw the graph of }\left(f^{\prime}\right) \text { in } \\
\text { Question (1)? }\end{array}$ \\
\hline & $\begin{array}{l}\text { Connect: Determine the links between } \\
\text { concepts and the interpretation of these } \\
\text { links, and show the conceptual } \\
\text { structure. }\end{array}$ & $\begin{array}{l}\text { Q5: Describe the behavior of the } \\
\text { graph } f(x) \text { in Question (1)? }\end{array}$ \\
\hline
\end{tabular}

